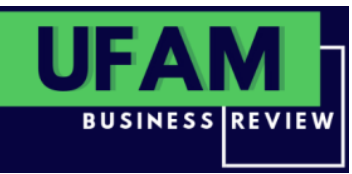

\title{
Políticas Públicas para a Educação Intercultural de Roraima: um Estudo sobre as Mediações Necessárias
}

\section{Public Policies for Roraima's Intercultural Education: A Study of the Necessary Mediations \\ Políticas Públicas para la Educación Intercultural De Roraima: Un Estudio de las Mediaciones Necessárias}

\author{
Graciete dos Santos Araújo ${ }^{1}$ \\ Professora: Universidade Federal do Amazonas - UFAM/AM \\ gracietesantosaraujo@gmail.com \\ http://lattes.cnpq.br/7968196662372020 \\ https://orcid.org/0000-0002-5084-4055 \\ Marquiza Castro de Almeida ${ }^{1}$ \\ Professora: Universidade Federal do Amazonas - UFAM/AM \\ maquizaca@gmail.com \\ http://lattes.cnpq.br/9770910899086151 \\ https://orcid.org/0000-0002-0451-889X \\ Carmem Véra Nunes Spotti ${ }^{1}$ \\ Professora: Universidade Federal do Amazonas - UFAM/AM \\ carmemspotti@bol.com.br \\ http://lattes.cnpq.br/9770910899086151 \\ https://orcid.org/0000-0002-0451-889X
}




\title{
Resumo
}

O artigo discute sobre a implementação de políticas públicas no Estado de Roraima na perspectiva da educação intercultural, tanto em relação a sua formação social quanto frente à maciça imigração de estrangeiros e migração indígena. Tem como objetivo a compreensão da criação de políticas para a inclusão dos grupos socioculturais que estão inseridos no espaço escolar de Roraima. O movimento migratório é um aspecto presente na globalização, levado por vários fatores, sejam econômicos, políticos ou sociais. Esta pesquisa é documental e bibliográfica e, tem como aporte os estudos de Boaventura (2006) e Carnoy (2003), entre outros, que tratam dos direitos humanos para uma educação intercultural. Políticas públicas precisam ser implantadas, afim de que seja ofertado um ensino que contribua para a prática pedagógica libertadora. Portanto, o desafio é conceber projetos coletivos que preservem e garantam o direito, reconhecendo as diferenças e culturas dos alunos, um desafio para a educação Roraimense.

Palavras-chave: Política públicas. Globalização. Educação. Intercultural. Escola. Professor.

\section{Public Policies for Roraima's Intercultural Education: A Study of the Necessary Mediations}

\begin{abstract}
The article discusses the implementation of public policies in the State of Roraima from the perspective of intercultural education, both in relation to their social formation and in the face of massive foreign immigration and indigenous migration. It aims to understand the creation of policies for the inclusion of socio-cultural groups that are inserted in the school space of Roraima. The migratory movement is an aspect present in globalization, driven by various factors, whether economic, political or social. This research is documentary and bibliographic and has as its basis the studies by Boaventura (2006) and Carnoy (2003), among others, that deal with human rights for an intercultural education. Public policies need to be implemented in order to offer teaching that contributes to liberating pedagogical practice. Therefore, the challenge is to design collective projects that preserve and guarantee the right, recognizing the differences and cultures of students, a challenge for Roraimense education.
\end{abstract}

Keywords: Public policy. Globalization Intercultural education. School. Teacher

\section{Políticas Públicas para la Educación Intercultural de Roraima: Un Estudio de las Mediaciones Necesarias}

\section{Resumen}

El artículo analiza la implementación de políticas públicas en el estado de Roraima desde la perspectiva de la educación intercultural, tanto en relación con su formación social como frente a la inmigración extranjera masiva y la migración indígena. Su objetivo es comprender la creación de políticas para la inclusión de grupos socioculturales que se insertan en el espacio escolar de Roraima. El movimiento migratorio es un aspecto presente en la globalización, impulsado por diversos factores, ya sean económicos, políticos o sociales. Esta investigación es documental y bibliográfica y tiene como base los estudios de Boaventura (2006) y Carnoy (2003), entre otros, que abordan los derechos humanos para una educación intercultural. Es necesario implementar políticas públicas para ofrecer una enseñanza que contribuya a liberar la práctica pedagógica. Por 
lo tanto, el desafío es diseñar proyectos colectivos que preserven y garanticen el derecho, reconociendo las diferencias y culturas de los estudiantes, un desafío para la educación roraimense.

Palabras clave: Políticas públicas. Globalización. Educación intercultural. Escuela. Maestro 


\section{INTRODUÇÃO}

Quando falamos em interculturalidade nos baseamos na proposta intercultural em que "as relações de identidade e diferença que se desenvolvem em movimentos sociais assim como na educação popular e escolar" (Fleuri, 2002, p. 01) tem ganhado força na busca do reconhecimento das identidades. Esta interculturalidade é bem evidenciada em Roraima, pois o estado é formado por migrante oriundos de várias partes do país, principalmente da região nordeste, por indígenas e imigrantes guianenses, venezuelanos e haitianos, entre outros.

Para Santos, (2018, p. 21)

Roraima é um Estado que se insere no contexto das migrações, principalmente por constituir-se em um lugar de recepção de grande fluxo de pessoas brasileiras e de outros países. Consequentemente, evidenciou a condição fronteiriça de Roraima ao destacar a tríplice fronteira Brasil-Venezuela-Guiana como um eixo de integração além da floresta amazônica, onde as pequenas cidades podem ser definidas como ponto de apoio às "estratégias de sobrevivência".

Essa condição fronteiriça traz uma variedade cultural que tem crescido com a entrada maciça de imigrantes de outros países que vivem em situação de crise sócio- econômica, como os haitianos, guianenses e, em sua maioria, os venezuelanos. Dados da Polícia Federal de acordo com BRASIL (2019) dos 88.820 imigrantes estrangeiros, que solicitaram refúgio em Roraima, 83.062 são venezuelanos. Vale salientar que a imigração venezuelana mostrou os primeiros indícios de seu êxodo em 2015 e alcançou seu ápice entre 2017 a 2019. É uma média de aproximadamente 3.563 venezuelanos registrados adentrando o país diariamente (Brasil, 2019).

Por conta dessa entrada de estrangeiros no estado, ocorreram impactos econômicos, sociais, culturais e, principalmente educacionais, tanto no âmbito estadual quanto municipal. A Secretaria Estadual de Educação e Desporto informa que as escolas estaduais receberam, no ano letivo de 2018, uma demanda de 1.361 alunos venezuelanos, 27 haitianos, 15 guianenses e um número bem menor de outras nacionalidades (SEED/RR, 2018). Muitos destes alunos não portavam documentos, tais como certificado de escolarização informando o nível de estudo, histórico escolar e documentos pessoais, para efetivação da matrícula. Entretanto, para não estar à parte da escolarização, permaneceram como alunos ouvintes e não foram incluídos no censo escolar até que legalizassem sua situação.

No âmbito educacional o estado tem a obrigação de gerenciar políticas para o atendimento de alunos, sejam eles imigrantes ou não, proporcionando a inclusão, daqueles que vivem à margem dos espaços escolares. Portanto, é de suma importância compreender, quais políticas públicas têm sido implementadas pelo Governo do Estado de Roraima, por meio da Secretaria de Estado da Educação e Desporto de Roraima (SEED-RR), na inclusão dos diferentes grupos socioculturais atendidos nas escolas públicas da capital.

Não se trata somente de recebê-los na escola, mas de efetivamente oferecer condições de aprendizagem, de ter uma formação crítica, reflexiva, de forma a proporcionar a sua autonomia e a participação cidadã. Além disso, garantir condições para permanência na escola, de apropriação do conhecimento da humanidade, até mesmo para compreender as relações sociais que o levaram a sair do seu país e os problemas sociais enfrentados por eles cotidianamente. Neste sentido, este 
artigo objetiva compreender a necessidade urgente da implementação de políticas públicas para uma educação intercultural nas escolas estadual da capital do Estado de Roraima.

Atualmente, de acordo com dados oficiais do censo escolar de 2018, as escolas da capital têm recebido uma mescla de alunos, que vai desde discentes de diferentes classes sociais, credos, culturas, com necessidades especiais, indígenas, campesinos, imigrantes de outros estados brasileiros, imigrantes da República Federativa da Guiana, República Federativa da Venezuela e República do Haiti.

É preciso lembrar que a escola é um espaço que agrega várias raças e culturas e precisam ter uma atenção diferenciada para tamanha diversidade. Ela tem um papel importante na inclusão destes alunos a fim de que todos possam gozar dos direitos a educação com igualdade e serem respeitados e reconhecidos quanto as suas diferenças.

Assim, a SEED-RR promotora e administradora da educação, deve criar junto às escolas e instituições formadoras conveniadas a formação continuada aos docentes visando sempre a aprendizagem dos alunos por ela atendidos. Também está intrínseco ao professor a busca por novos conhecimentos, desenvolver novos saberes acompanhando a dinâmica da sociedade, pesquisando e refletindo sobre sua prática frente a tais mudanças sociais. Em geral os cursos de graduação não oferecem a educação intercultural como disciplina curricular, e consequentemente implica na não identidade intercultural do professor.

A educação intercultural vem trazer um atendimento aos alunos com reconhecimentos das diferenças culturais e a inter-relação que estão imersos afim de minimizar os conflitos indenitários e assegurar o direito ao ensino de qualidade.

Esta pesquisa caracteriza-se como uma pesquisa documental e bibliográfica em sua forma. Os documentos oficiais disponíveis nos sites da secretaria e instituições reconhecidas, serviram de aporte para análise quanto as políticas públicas para a educação intercultural em Roraima. $\mathrm{O}$ levantamento bibliográfico é de autores que tratam da educação interculturalidade em uma visão globalizada, e o papel do Estado nas políticas públicas educacionais e na formação dos professores.

Este artigo divide-se em três partes: na primeira parte discorremos sobre o papel do estado quanto as políticas públicas para promoção de uma educação intercultural. Na segunda, tratamos da globalização e das políticas públicas que devem estar compromissadas a educação intercultural. Já na terceira debatemos sobre a formação continuada do docente para a práxis em uma educação intercultural. Finalizamos o estudo com as considerações finais analisando o papel do Estado na elaboração e promoção de políticas públicas para educação intercultural no mundo globalizado e verificando a importância da formação dos professores, para efetivação dessa educação analisando os desafios e perspectivas para o atendimento aos diversos grupos socioculturais atendidos.

\section{O PAPEL DO ESTADO DE RORAIMA QUANTO ÀS POLÍTICAS PÚBLICAS PARA A EDUCAÇÃO INTERCULTURAL}

A educação é de competência da União, Estados e Municípios. O Plano Nacional de Educação, Lei 13.005 (2014) estabelece metas e estratégias para a educação do país. São monitorados e avaliados em conjunto com o Ministério da Educação e Cultura (MEC), Câmara Nacional de Educação, 
Conselho Nacional de Educação (CNE). Os estados desenvolvem suas atividades por meio de suas Secretarias de Educação.

Neste sentido, a Secretaria de Estado da Educação e Desporto do Estado de Roraima (SEED-RR) tem a incumbência de organizar, desenvolver e manter o sistema de ensino, integrando as políticas públicas e planos educacionais da união e do estado nos termos da Lei de Diretrizes e Bases da Educação Nacional em vigor. A Secretaria estabelece e implementa planos da União e, a partir de dados coletados nas escolas, elabora planos e projetos estaduais que garantam o ensino público a todos e, este com qualidade para a formação cidadã.

Todos os anos a Secretaria realiza um censo escolar que, a partir de dados levantados in loco, traça metas com o objetivo de oferecer um ensino de qualidade cumprindo com determinações do Plano Nacional de Educação. De fato, toda a informação pertinente ao ensino em Roraima é de interesse desta Secretaria de Educação (Roraima, 2018).

Cerca de aproximadamente três anos, devido às crises existentes em alguns países subdesenvolvidos, o Estado de Roraima recebeu muitos imigrantes, como citado anteriormente e, segundo o Censo Escolar de 2018 (Roraima, 2018), as escolas da capital, do interior e as indígenas, receberam cerca de 1.410 alunos, sendo que 1.361 são venezuelanos e 49 de outros países. Este indicativo não considerou os alunos indígenas brasileiros (que não falam o português) e indígenas venezuelanos (que falam sua língua nativa).

A Lei No 13.005 do Plano Nacional de Educação (PNE), em seu Art. 4ํㅜ, sobre a importância e função do Censo Escolar. Assim, as informações levantadas pelo referido Censo colaboram com a fomentação de estratégias para implementação de projetos na busca de equiparar a educação com a nacional. Devido à grande quantidade de escolas, transferências e chegada de alunos, os dados podem oscilar.

Com relação à formação dos professores, o Governo do Estado de Roraima criou, por meio da Lei N 611 de 22 de agosto de 2007, o Centro Estadual de Formação dos Profissionais da Educação de Roraima - CEFORR para fomentar a formação inicial e continuada, capacitação e atualização para professores e profissionais da educação. De acordo com a referida Lei, em seu Art. $3^{\circ}$ (Roraima, 2007), compete ao CEFORR,

I - coordenar a elaboração e execução da política e do plano estadual de educação, de acordo com a legislação vigente e obedecendo às diretrizes e normas do Sistema Estadual de Ensino e do Conselho Estadual de Educação; II - promover o desenvolvimento da formação continuada, visando ao atendimento das demandas profissionais por aperfeiçoamento para o trabalho, em consonância com as políticas de governo; III - articular a cooperação entre órgãos públicos municipais, estaduais, federais e/ ou privados na implantação de novas iniciativas na área da formação continuada; e IV - celebrar convênios, contratos, acordos e parcerias, visando à promoção da formação continuada no Estado.

O CEFORR, dentre os cursos de formação continuada, realizou em 2018, um "Seminário Internacional Criança e Adolescente: Bem Comum, Educação Intercultural para a inclusão de crianças e adolescentes migrantes", em parceria com o Fundo das Nações Unidas para a Infância UNICEF, Fraternidade Federação Humanitária Internacional - FFHI, Projeto O Bem Comum, 
Secretaria Estadual de Educação e Desporto de Roraima - SEED/RR, Universidade Federal de Roraima - UFRR, Universidade Estadual de Roraima - UERR e Visão Mundial objetivando debater sobre esta problemática educacional e traçar metas para desenvolver trabalho de formação continuada. Este evento proporcionou a indicação de demandas para elaboração do projeto "Formação Continuada para o Contexto de Imigração Emergencial: interfaces e abrangências em fronteiras", ainda em fase de conclusão. Este projeto objetiva discutir a formação de professores para preparar os profissionais da educação em relação a esta demanda de forma a contemplar a interculturalidade. Neste sentido, uma das discussões em pauta está o ensino da língua dentro da perspectiva da didática das línguas tendo em vista a formação do aluno e sua competência comunicativa.

\section{A GLOBALIZAÇÃO E AS POLÍTICAS PÚBLICAS COMPROMISSADAS A EDUCAÇÃO INTERCULTURAL}

Com a mundialização da economia e culturas nacionais, o mundo sofreu transformações que atingiram os diversos espaços, inclusive a educação. Com o objetivo dessa interação planetária, fortemente influenciada pela informação e inovação como afirma (Carnoy, 2003, P.28), assim chegou a mundialização. Essas mudanças trouxeram grandes e fortes reformas para o sistema educacional como os papéis do Estado, escola, professor, ensino/ aprendizagem agora questionados, a fim de atender a nova ordem econômica mundial e, tais mudanças atendem as ideologias ante estatais.

A mundialização é tão extensa que nada fica fora dos seus interesses e nem de suas ideologias. Carnoy (2003, p.24,25) traz uma síntese das consequências para os governos dos países, a qualidade dos sistemas educacionais e as redes de informações. Não há como negar que tais reformas, alicerçadas na competividade, visa a produtividade, visto que o lucro é fator desencadeador de tais mudanças.

Para Santos (2006) estas transformações ocorrem por vias de processos, cujo âmbito é global, e atendem as exigências de acumulação capitalista. Nada pode se esquivar da globalização, pois os países simplesmente foram feitos globalizados. Embora a globalização impulsionada por tantas mudanças se veja desafiada a superar os problemas gerados dentro dela, fica a responsabilidade do próprio Estado descobrir os recursos disponíveis, fazer uso deles para atender as necessidades da sociedade. Essas políticas públicas para a educação precisam alcançar a raiz dos problemas e não é possível pensar sobre elas deixando de fora o Estado (Fávero, 1987).

É papel de o Estado prever políticas públicas para atender a população mais necessitada, mas para que isto ocorra ele precisa saber o que quer para sociedade como um todo e a sociedade precisa estar bem convicta e ativa para exigir. Fávero (1987) diz que é necessário privilegiar instituições e movimentos sociais e populares a fim de que as políticas educacionais beneficiem os setores mais necessitados, que haja uma retomada de um projeto social amplo e projeto educativo na busca da construção de uma sociedade democrática.

Para compreender melhor a globalização Santos (2006) diz haver quatro processos da globalização que dão origem a dois modos de produção que são: o localismo globalizado, globalismo localizado, cosmopolitismo insurgente e subalterno e patrimônio comum da humanidade. O localismo globalizado é o processo em que determinado fenômeno, entidade, condição ou conceito local é 
globalizado com sucesso, pelo reconhecimento de uma cultura hegemônica imposta de uma determinada ordem internacional. O globalismo localizado são impactos específicos sofridos nos locais das práticas e imperativos transnacionais advindos dos localismos globalizados. Estas são forças hegemônicas que se propõe a impor diferentes hierarquias no capitalismo.

Para Sacavino (2003) o cosmopolitismo é a forma de organização transnacionais de estadosnações, regiões, classe ou grupos sociais na defesa dos interesses comuns, que se beneficia das possiblidades de interação transnacional, criadas pelo sistema mundial. Esta é a mesma compreensão de Santos (2006) que diz que são resistências transnacionais organizadas que lutam contra os localismos globalizados e globalismos localizados. Isso é possível quando as sociedades organizadas lutam contra o regime hegemônico trazidos pelas globalizações.

O último processo de globalização contra hegemônica é "[...] a que se identifica e estrutura em torno dos interesses relativos ao patrimônio comum da humanidade (Sacavino, 2003, p.12)", ou "[...] consiste na emergência de lutas transnacionais por valores, ou recursos que, pela sua natureza, são todos globais como o próprio planeta (SANTOS, 2006, p. 441)". É tudo o que diz respeito a humanidade, de preservação dos recursos naturais de manutenção da vida no planeta.

A gestão dessa nova ordem mundial não é somente lugar de submissão, mas também oportuniza, de uma forma bem conflituosa, o hasteamento da bandeira contra hegemônica. Essa luta é travada nos vários setores da economia internacional, que influencia diretamente na educação e é o foco desta discussão.

Para Carnoy (2003, p. 61,62) a mundialização suprimiu a educação com as reformas motivadas pelos imperativos financeiros defendidos pelas instituições monetárias internacionais, e propôs reduzir os gastos com o ensino público. A educação além de sofrer com os imperativos financeiros de controle internacionais trazidos pela globalização, ainda pode desconhecer a existência de processos contra hegemônicos afetando diretamente a formação cidadã social. Segundo Gentilli (2001) que a redução dos gastos públicos questiona a possibilidade de elevar os níveis da qualidade da educação.

Desta forma, a falta de visão do Estado na promoção da educação intercultural, para atender à grande diversidade de grupos étnicos, raça e povos imigrantes, atualmente ocorrida em Roraima, tem gerado graves consequências para a formação cidadã do aluno brasileiro e o direito à educação aos imigrantes garantida pelos direitos humanos. Para Sacavino,

A proposta de radicalização democrática para a construção de uma nova ordem mundial tem como um de seus pilares fundamentais os direitos humanos, entendido como conjunto de princípios universalmente aprovados, transformados em um dos códigos morais e éticos atuais do mundo globalizado (Sacavino,2003, p.14).

Assim, os diretos humanos é uma forma de globalização contra hegemônica, e de acordo com Santos (2006, p. 445-6) "[...] precisa ser reconceitualizada como intercultural, [...] pois o indivíduo possui uma dignidade absoluta e irredutível que tem que ser defendida da sociedade ou do Estado". Nesta visão dos direitos humanos há espaço para o diferente, para o respeito a diversidade, para a promoção da cidadania, mas não uma cidadania mundial e sim uma que reconheça a existência e promova a inter-relação entre essas culturas diferentes e locais. 
De acordo com Sacavino (2003) "[...] a cidadania se concebe dirigida em função do mundo pluriétnico e multicultural, respeitando as comunidades com suas expressões próprias e única da espécie humana". Em um mundo globalizado as migrações e imigrações são comuns, as culturas se mesclam e podem convivem de forma harmônica, desde que haja uma cultura de aceitação do diferente.

Políticas públicas para a educação devem ser criadas à medida que a sociedade sofre transformações, o Estado precisa estar atento a tais mudanças buscando e propondo ações que oportunizem o preparo dos professores e profissionais de educação, oferecendo uma cidadania global. Para Sacavino (2003, p.19) “A globalização da política ética supõe respeito ao diferente, ações e reformas inclusivas e solidárias, apoio e promoção dos processos políticos, sociais e culturais".

Gentilli (2001, p. 47) nos traz uma afirmação grave, mas que nos diz muito da educação, “[...] A escola está mudando para continuar sendo a mesma. Haja desencanto". Não podemos deixar que alunos passem pela escola como uma tarefa a ser cumprida, sem deixar de reconhecê-lo como um cidadão importante num mundo em sucessivas transformações sociais. Essa luta deve ser também de interesse social, de luta contra o regime hegemônico, de resistência, luta contra a exclusão e discriminação, pelos direitos interculturais, que desenvolvam ações no interior da escola ou fora dela, que atendam aos interesses sociais para uma sociedade emancipada, a partir de uma formação cidadã crítica e reflexiva da realidade, com um ensino de qualidade.

Para Montoan (2011) o ensino de qualidade definido pelas condições do trabalho pedagógico tem consequências diretas na formação de rede de saberes e de relações, que se encontram na busca do conhecimento. Esses conhecimentos não são somente para o trabalho, mas para valorização da vida, de compreensão das desigualdades sociais e o rompimento com as ideologias de classe. Montoan (2011, p.61) afirma que "para ser de qualidade a escola precisa ser espaços educativos em que se constrói a personalidade humana autônoma, crítica, em que se aprende a ser pessoa". Importa para a escola quem são os alunos e o que eles trazem de suas experiências de vida, se o aluno está aprendendo, e se não aprende o porquê deste impedimento. Acrescenta Montoan (2011) que ambientes educativos de ensino valorizam as diferenças, respeito mútuo, exemplo dos professores, organização e ministração das aulas, clima sócio- afetivo cultivado pela comunidade escolar.

De fato, observamos trabalhos isolados de algumas escolas da capital, de comunidades escolares que querem fazer a diferença e desenvolvem projetos de inclusão social, de promoção da interrelação, de aceitação do diferente. A questão se refere a um tema complexo e, ao mesmo tempo, central para a compreensão crítica do papel social que cabe à escola em uma sociedade democrática com a formação ética dos cidadãos.

Gentilli afirma que,

Esse é um dos desafios fundamentais de uma educação que contribua para quebrar o encanto do desencanto, para nos livrar da resignação, para recuperar ou para construir nossa confiança na possibilidade de uma sociedade baseada em critérios de igualdade e de justiça, uma sociedade na qual a proclamação da liberdade individual não questione os direitos e a felicidade de todos. Uma sociedade em que a diferença seja uma possibilidade para a construção de nossa autonomia, não o argumento para 
legitimar injustas desigualdades econômicas, sociais e políticas. (Gentilli,2001, p. 54).

Embora a escola, com seus pares, ofertem minimamente uma educação com ações interculturais, de atendimento aos diversos alunos inseridos nos espaços escolares, o Estado tem a obrigação de desenvolver políticas educacionais que alcance todas as escolas. Desta forma, “o estudo das escolas públicas revela que, apesar da precariedade, existem projetos acontecendo que mostram uma prática transformadora (KRUPPA, 2001,p.37)”. Que sejam por ele coordenadas, cumprindo com sua função de ofertar cursos de formação e formação continuadas que visem atender esta diversidade de alunos indígenas, imigrantes, campesinos, negros, de qualquer credo, classe social ou cultura e, oferecer a eles uma formação digna, de valorização da identidade cultural.

\section{FORMAÇÃO CONTINUADA DOCENTE PARA A EDUCAÇÃO INTERCULTURAL}

Pensar na formação docente atualmente é pensar em uma engrenagem complexa e necessária. Ou seja, pensar na identidade do educador, aspectos e requisitos da formação seja ela inicial ou continuada, a fim de acompanhar as transformações sociais e sempre buscar superação das ideologias dominantes.

A formação cidadã é um direito básico garantido, por lei, ao aluno. Essa formação ocorre dentro da escola e, deve ser de qualidade. Para que ela se efetive, a escola deve estar comprometida e ter a compreensão do que é ser um cidadão. Para Kruppa (2001, p. 18)

Efetivar a cidadania significa ressignificar formas e conteúdos, tempos e espaços de ações, permanentemente, em que o "eu" e o "outro" possam se fundir em um "nós" de direitos iguais, em que as diferenças de cada um possam ser respeitadas sem que isso signifique desigualdades.

Todos precisam estar envolvidos com esta missão, para que o direito se torne do grupo e, mesmo com diferenças de cultura podem ter os mesmos interesses de exercer sua cidadania com consciência afim de minimizar as desigualdades sociais. O incentivo ao individualismo, a manutenção de uma classe que determina o a identidade e como formar este cidadão não pode mais existir. Kruppa (2001) diz que ao contrário da afirmação do individualismo devemos promover a construção de espaços coletivos, em que conjuntamente com os interessados possam instigar o surgimento de políticas públicas para melhores condições de educação, saúde, emprego e habitação.

Oliveira (1995, p.16) afirma que após o "capitalismo monopolista”, a escola começa a receber não somente o filho da classe média, mas os fillhos dos subalternos, ocasionando uma mescla de culturas que passarão a dividir o mesmo espaço de aprendizagem e ter direitos iguais a formação cidadã. Os diferentes alunos poderão, portanto, ter acesso ao ensino, a desenvolver habilidades, a compreender e apropriar-se do conhecimento elaborado pela humanidade. Essa busca deve ser contínua afim de que, de acordo com Oliveira (1995) essa tomada de consciência da diversidade avance até o ponto em que não seja necessário modificar a condição geral existente. Com o objetivo de que se torne uma prática de identificar as "[...] diferenças individuais como individualizada" (Oliveira,1995, p.17). 
Os alunos ao chegarem na escola trazem consigo conhecimentos e características socioculturais adquiridos ao longo da vida, que o identificam com sujeitos que pertencem a um grupo. Para Whitaker (1995) o que se tem na escola é uma "multiinfância" que são diferentes modos de ser criança, demarcadas por linhas que se cruzam no espaço social escolar público. A escola não pode ficar omissa a essa gama de diversidade, estabelecendo objetivos considerando um modelo de aluno, com uma cultura igual à dos demais, ela tem que ser inclusiva realizando a "cidadania dos nós" de Kruppa (2001). O que se busca é uma escola com compromisso social que atenda os anseios da sociedade na reconstrução de uma sociedade mais igualitária que privilegie a todos.

De fato, a escola é um lugar de formação de consciência e de lutas, de busca pelo conhecimento elaborado pela sociedade e deve ser ouvida quanto a sua compreensão social. De acordo com Kruppa (2001, p. 26), a escola inclusiva é aquela que pode realizar a "cidadania dos nós", romper com as desigualdades e com o preconceito a sociedade quer uma escola que se deixe ocupar pelas questões atuais, que contribua no fortalecimento das lutas de interesses sociais e na solução de problemas concretos de cada comunidade e do país. A sociedade está em constante transformações e os obstáculos para a efetivação da educação também mudam e a escola deve estar acompanhando tais câmbios, a fim de atender essas necessidades, dentre elas a inclusão social.

O espaço escolar deve promover a inclusão, eliminando as diferenças sociais que são obstáculos para a aprendizagem dos alunos. Para Campos (1995) a escola deve questionar seu papel social e os professores refletirem sua competência técnica e seu compromisso político social. $\mathrm{O}$ aluno não tem só o direito à educação, mas também a permanência do mesmo na escola. Kruppa (2001) afirma que a discussão do projeto político pedagógico que busca defender da escola pública tem que fazer parte da agenda dos que buscam a luta por ela".

A luta inicia pela busca de incentivos do estado, no cumprimento de suas atribuições quanto ao ensino de qualidade. A escola segundo Gomes (1995) tem o papel de criar um trabalho em colaboração com organismos públicos e as famílias envolvidas a fim de possibilitar o planejamento de estratégias de ação que atuem na compreensão dos problemas e na construção de soluções para tais embates. Políticas públicas devem ser promovidas pelo Estado que é responsável pela educação oferecida para a população e, se não cumprir com esta tarefa precisa ser cobrado.

Para Oliveira (1995) é uma tarefa que a escola, em um processo desconhecido, como agência criada para formar o sujeito como cidadão, vai concorrer. Ela, por sua vez, frente aos obstáculos enfrentados, no ato de oferecer uma educação de qualidade, não pode se eximir de buscar soluções para os problemas que surgirem, cumprindo com sua função social. Neste sentido, "o fundamental é exercermos ativamente nossa cidadania para ampliarmos as margens de êxito desses projetos (Kruppa, 2001, p.37)".

Para uma sociedade que muda, é necessária uma escola que acompanha essas mudanças, que tenha uma nova visão, que estabeleça novas metas para alcançar a aprendizagem dos alunos. Segundo Oliveira (1995, p.29)

Para construir uma nova escola, uma nova sociedade, uma nova racionalidade, tornam-se necessários novos patamares de teoria e de prática que partam da diversidade, atravessem processos de desocultamento crítico e atinjam horizontes abertos à palavra plural, à democracia. 
A escola, nesta visão, não pode desconsiderar o conhecimento que os alunos trazem alegando não ser conhecimento científico, não ser cultura. Oliveira (1995) diz que ao adentrar a escola, esse aluno, traz ideias, emoções, interpretações do mundo formadas em sua cognição, centrado em suas emoções, adquiridos na sua convivência com o meio. Da sua realidade ele fala com propriedade, sem dúvidas, e gostaria que o que ele vivência pudesse ter relação com o que aprende na escola, para que com intrepidez possa participar da construção de seus conhecimentos, com autonomia.

O professor, por sua vez, precisa reconhecer-se como um formador de opinião, que compreende como ocorrem as relações sociais desiguais e busca oportunizar seus alunos ampliando seus conhecimentos. Kruppa (2001) defende uma pedagogia que visa dimensões da pessoa humana, a criação de um espaço educativo firmado em práticas democráticas, dimensão educativa do trabalho, cultura e história do povo. Enquanto não houver uma compreensão política por parte do professor, nada poderá ser mudado, ele permanecerá alienado, sem esperança de uma sociedade melhor. Portanto, Sacavino (2003) afirma que, desse modo, ser educador é ter um compromisso político, exige um posicionamento diante da realidade e, a partir desta consciência, liberta o sentimento de corresponsabilidade pela vida em sociedade.

Freire (2013) é muito enfático em afirmar que "ser educador", nessa perspectiva crítica, exige um compromisso com a ética, a cidadania, a competência, a criticidade, a alegria, a esperança. $\mathrm{O}$ autor traz a importância dos saberes necessários à prática docente, a percepção para a escolha destes saberes, sempre identificando as ideologias a fim de cumprir com a tarefa de ensinar. É preciso mudar o "eu" professor para saber o que queremos e para buscar os elementos necessários para o combate sem jamais perder as esperanças na educação.

O papel do professor é muito mais que ensinar conteúdo, é formar a consciência política do aluno para ser ativo na sociedade. Para Moura (2011, p. 54) "Cabe a nós, educadores, compreendermos nosso papel nesse jogo de relações que constitui a dinâmica social e educacional”. Essas relações de poder são estabelecidas pelas globalizações, mas precisam ser compreendidas na sua integra para não reproduzir tais ideologias, mas lutar pela valorização das culturas, do ser que existem no ambiente escolar.

Os alunos que chegam na escola trazem consigo o conhecimento de mundo, que deve ser um ponto de partida para encaminhá-lo ao um outro nível mais elevado, o conhecimento científico, de novas descobertas. De acordo com Oliveira (1995) a escola quanto a sua função educativa, baseado no real aluno que atende, some os conhecimentos que adquirido em seu meio social, conhecimento das múltiplas culturas existentes entre os discentes, conhecimento de seus limites e potencial para contribuir com a formação crítica e emancipadora.

Essa cultura em que o aluno está inserido, como ele se identifica neste meio social, é elemento importante para compreender como se dá as relações sociais e, que precisamos lutar por um mundo inclusivo, de cooperação. Para Moura (2011) essa marca, a individualidade pertencente ao ser social, que faz com que sua identidade, original, seja preservada e, o diferencie como indivíduo, motivando desenvolver todo o seu potencial criador, a fim de valorizar e desenvolver essa identidade no mundo.

Oliveira (1995) aborda que também é papel da escola fazer o reconhecimento real dos impactos das diferenças de classes sociais nos alunos, para a partir de então poder cooperar a fim de que o 
próprio aluno compare sua formação originária antes da reflexão e seus percursos com a formação cultural desenvolvida pela escola. A compreensão da divisão de classe, das realidades que os alunos vivenciam precisam ser trazidas para reflexão, para que haja uma formação da consciência política, de aceitação e respeito mútuo das culturas envolvidas neste processo de aprendizagem, e de esperança nas mudanças na sociedade cheia de discriminação, para uma sociedade cooperativa e humana.

\section{CONSIDERAÇÕES FINAIS}

O papel do Estado é de suma importância no controle e na promoção de políticas públicas educacionais e precisam observar as mudanças que ocorrem na sociedade para, a partir delas, estabelecer metas. Quando este papel não é cumprido há a sobrecarga da escola, que sempre recai sobre o professor que precisa desenvolver projetos de forma independente para minimizar os efeitos dos problemas.

Mesmo com forças contrárias produzidas pela globalização é possível lutar com artifícios contra hegemônico produzidos dentro ela. É o que se vê quando o Estado se omite de realizar suas tarefas e a sociedade precisa se mover, seja por ações cosmopolitas de lutas por meio de movimentos populares criar projetos de combate à discriminação social, de exclusão e busca de uma educação de qualidade.

Os direitos humanos, embora com princípios, pode ser reconstruído numa perspectiva intercultural, a fim de reconhecer as diferenças culturais em uma criação de ambiente sócio afetivo comprometido com aprendizagem dos diversos alunos. Esses direitos estão imbricado na formação cidadã global, que considera características globais sem desconsiderar as locais.

A sociedade também tem uma arma que numa construção coletiva juntamente com a sociedade pode propor estratégias para implementar a educação intercultural dentro do centro das atividades desenvolvidas neste espaço. As ações dentro e fora da escola deve ser de busca pela autonomia do aluno, que ela ofereça condições estruturais para atender os alunos, com alimentação adequada, e que os professores sejam motivados pelos cursos oferecidos pelo Estado, a identidade intercultural para o atendimento a diversidade.

A escola deve promover um ambiente de respeito mútuo, de aceitação das diferenças e que o direito à educação seja igual para todos, que a partir das múltiplas culturas existentes dentro das escolas sejam um berço para novos conhecimentos. Os professores precisam assumir esta postura intercultural de não excluir os alunos, de respeitar suas culturas e combater quaisquer formas de discriminação, de valorizar as culturas dos alunos e suas experiências vividas, para assim a partir destas introduzir o conhecimento científico. É preciso formar o aluno numa consciência política, de compreensão das desigualdades sociais e a criação de caminhos que levem a mudanças sociais de todos, visando um bem comum.

\section{REFERÊNCIAS}

AMABILE, Antônio Eduardo de Noronha. Políticas públicas. In: CASTRO, Carmem Lúcia Freitas de; GONTIJO, Cynthia Rúbia Braga; AMABILE, Antônio Eduardo de Noronha. Dicionário de Políticas Públicas. Barbacena: EDUEMG, 2012. 
BRASIL. Plano Nacional de Educação: Lei $N^{o} 13.005$ de 25 de Junho de 2014

<http://www.planalto.gov.br/ccivil_03/_Ato2011-2014/2014/Lei/L13005.htm> Acesso: 04/11/18 . Policia Federal: Ministério da Justiça e Segurança Pública. Sistema de Tráfego Migratório. São Paulo: Sistema de Tráfego Internacional: Abril/2019

$\langle$ http://www.pf.gov.br/servicos-pf/imigracao/apresentcao-policia-federal-ate-abril-de-019.pdf $>$

Acesso em:23/07/19

CARNOY, Martin. (2003). Mundialização e reforma na educação: o que os planejadores devem saber. Brasília: Unesco Brasil, IIPE.

FÁVERO, Osmar. Comentários. In: BRASIL, Ministério da Educação Instituto Nacional de Estudo e Pesquisa Educacionais. Políticas públicas e educação. Brasília: INEP; São Paulo; Fundação Carlos Chagas, Campinas UNICAMP,1987. Séries Encontros e Debates 1.

FLEURI, Reinaldo M. (2002). Educação intercultural: a construção da identidade e da diferença nos movimentos sociais. Revista Perspectiva, Florianópolis, 2002.

FREIRE, Paulo. (2013). Pedagogia da autonomia. Saberes necessários à prática educativa. Ed. Rio de Janeiro: Paz e Terra, 2013.

GENTILI, Pablo. (2001). Escola e cidadania em uma era de desencanto. SILVA, Shirley; VIZIM, Marli (Orgs.). Educação especial: múltiplas leituras e diferentes significados. Campinas, SP: Mercado de letras.

GOMES, Heloisa Szymanski R. (1995). De que família vêm nossos alunos? In: SERBINO, Raquel Volpato; GRANDE, Maria Aparecida Rodrigues de Lima (Orgs.). A escola e seus alunos: Estudos sobre a diversidade cultural. São Paulo: UNESP. (Pg. 81- 89)

KRUPPA, Sonia Maria Portella. As linguagens da cidadania. SILVA, Shirley; VIZIM, Marli (Orgs.). Educação especial: múltiplas leituras e diferentes significados. Campinas, SP: Mercado de letras, 2001.

MANTOAN, Maria Teresa Eglér (Org.). (2011). O desafio das diferenças nas escolas.4º. Ed. Petrópolis, RJ: Vozes.

MOURA, Margarida Seabra de. (2011). Revisando conceitos: o necessário exercício da construção da identidade a partir das diferenças. MANTOAN, Maria Teresa Eglér (Org.). O desafio das diferenças nas escolas. $4^{\circ}$. Ed. Petrópolis, RJ: Vozes.

OLIVEIRA, Newton Ramos de. (1995). Formações concorrentes. In: SERBINO, Raquel Volpato; GRANDE, Maria Aparecida Rodrigues de Lima (Orgs.). A escola e seus alunos: Estudos sobre a diversidade cultural. São Paulo: UNESP.

RORAIMA. Lei $n^{\circ} 611$ de 22 de agosto de 2007. Criação do Centro Estadual de Formação de Profissionais da Educação de Roraima.

UFAMBR, Manaus, v. 2, n.1, art. 4, pp. 34-48, janeiro-junho, 2020 http://www.periodicos.ufam.edu.br/ufambr 
<http://www.tjrr.jus.br/legislacao/phocadownload/leisOrdinarias/2007/Lei\%20Estadual\%20611 2007.pdf> Acesso: 04/12/18 as 17:45

- Secretaria de Educação e Desporto do Estado de Roraima. Censo escolar (2018)Provisório. Boa Vista: Censo Escolar, 2018.

SACAVINO, Susana. (2003). Democracia e cidadania na nova ordem mundial globalizada. In: CANDAU, Vera Maria; SACAVINO, Susana. (Orgs.). Educar em direitos humanos: construir democracia. $2^{\circ}$ Ed. Rio de janeiro: DP\&A.

SANTOS, Alessandra Rufino. Universidade Federal do Rio Grande do Sul, tese: INTERAÇÃO SOCIAL E ESTIGMA NA FRONTEIRA BRASIL/VENEZUELA: UM

OLHAR SOCIOLÓGICO SOBRE A MIGRAÇÃO DE BRASILEIROS E VENEZUELANOS, 2018

SANTOS, Boaventura de Souza dos. (2006). A Gramática do Tempo: para uma nova cultura política. 3. ed. São Paulo: Cortez.

SILVA, Gilberto Ferreira. Multiculturalismo e educação intercultural: vertentes históricas e repercussões atuais na educação.

WHITAKER, Dulce Consuelo Andreatta. (1995). Cultura escolar e espaço social. In: SERBINO, Raquel Volpato; GRANDE, Maria Aparecida Rodrigues de Lima (Orgs.). A escola e seus alunos: Estudos sobre a diversidade cultural. São Paulo: UNESP. 